\title{
Review of: "Finding 'common ground' on shifting sands: observations on the conflicts over product regulation"
}

\author{
Moira Gilchrist ${ }^{1}$
}

1 PMI Science

Potential competing interests: The authors are full-time employees of Philip Morris International

An alternative suggestion for 'common ground': listening to the people who really matter-the billion people in the world who smoke.

The recent Editorial "Finding 'common ground' on shifting sands: observations on the conflicts over product regulation" bemoans the tensions that currently exist within the 'tobacco control movement' due to the introduction of better alternatives to cigarettes. Strikingly, the editorial offers just one solution-devoid of any scientific inquiry-to advance global public health: "marginalise the tobacco industry", which the author criticizes for "vigorously embracing the idea of harm reduction". This proposed solution completely misses the point.

Businesses—and what they make - change over time because of scientific and technological advancements. In any other sector, it is unthinkable that companies with valuable expertise would be excluded from discussions on the development, commercialization and regulation of innovative technologies that fulfil consumer demand and improve lives. If tobacco companies are not involved in delivering innovations that provide better alternatives to adults who smoke, who will take their place? Who will take responsibility for realizing the benefits of the many innovations that already exist and are desperately needed to move adults who smoke to better choices en masse? We do not speak for the entire tobacco industry, but we do speak for Philip Morris International, and can reassure the author that we are doing exactly what consumers demand. Adults who would otherwise continue to smoke want better alternatives and we will continue to deliver them responsibly, and as fast as we possibly can.

The editorial presents a familiar, but false choice: "protecting children from attractively marketed, potentially dangerous and addictive products versus encouraging smokers to choose products believed to be less harmful that might also help them quit." The two are not mutually exclusive, as we have been able to demonstrate in the commercialization of our lead smoke-free product over the last five years. Adults have switched to it in their millions, completely abandoning cigarettes, whilst at the same time, youth use is extremely low. As such, we make no apology for "wedging" ourselves into the conversation, not due to a desire to "exploit existing disagreements", but out of a desire to make better alternatives available to adults who don't quit—as quickly as possible—wherever cigarettes are sold. It is perfectly possible to deliver effective regulatory frameworks that minimize the risks of youth and other unintended audiences from adopting nicotine products, whilst ensuring that the intended population have access to them.

The editorial describes new products popping up like "Whack-A-Mole" and embraces the fact that "different countries already take very different approaches" to smoke-free products in some sort of global observational experiment. Characterizations like this disregard the importance of bringing choices to adults who smoke and gloss over the fact that 
the fragmented global regulatory approach is creating unacceptable inequities for them. Many countries have regulated smoke-free alternatives to cigarettes, allowing adults to access them, and have information about them. But others have banned them, meaning that smokers there are faced with a discriminatory and binary choice: quit or continue using cigarettes.

People who smoke are, for the most part, completely unaware of the divisive policy battle that is going on above their heads and, frankly, they do not care. They want solutions. Most want to quit. But the reality is that the vast majority don't and a very large percentage of these people are interested in better alternatives to continued smoking. They do not care who brings those alternatives, what they care about is whether they like them, and whether they offer something better than their cigarettes. They are unconcerned about whether there's conflict and disagreement within the tobacco control movement. These people care about their own daily lives and choices. The bitter policy war that is raging is accompanied by misleading statements that are picked up in the news media every day. This rhetoric has had the unfortunate effect of confusing adults who smoke. They deserve to access smoke-free alternatives to cigarettes and they also deserve accurate information to guide their choices. And we are here to provide both, enabled by appropriate and clear regulations. Attempts to marginalize the tobacco industry will not solve the issue of smoking. There is an alternative to the author's suggested common ground: listening to the needs, wants and opinions of people who smoke. They are the ultimate decision-makers. They will decide what course of action they want to take, provided they are empowered to do so by science-based regulation.

\title{
Dr. Moira Gilchrist
}

Vice President Strategic and Scientific Communications

\author{
Mr. Antonio Ramazzotti \\ Vice President Consumer Insights
}

Notes:

Originally submitted as a Rapid Response to Tobacco Control on 25th February 2021. 